\title{
Recent progress in chemical measuring capabilities in INM as a result of EMRP/EMPIR Programme
}

\author{
Mirella Buzoianu, ${ }^{1, *}$, Mihail Radu ${ }^{1}$, and George Victor Ionescu ${ }^{1}$ \\ ${ }^{1}$ National Institute of Metrology, Sos.Vitan-Barzesti 11, 042122 Bucharest, Romania
}

\begin{abstract}
New metrology capabilities in chemical area are of great interest as they underpin the traceability of measurement results reported in environment, health or food sectors. To develop such capabilities a consistent research work is needed. Since 2009, the European Metrology Research Program (EMRP) enabled the National Institute of Metrology (INM) from Romania to join several Joint Research Projects (JRPs) in chemical field. Main outcomes of this helped INM in developing and implementing measurement capabilities in gas chromatography (GC) and inductive couple plasma mass spectrometry (ICP-MS). Accordingly, a brief review of the best practice achieved at INM after participating in ENV08 and SIB09 is described. Further, the European Metrology Programme for Innovation and Research (EMPIR) facilitated expanding the existing metrology capabilities/infrastructure within the frame of two research potential projects (RPOT) in chemical field. Aspects regarding developing ICP-MS technique for measuring mass fractions of elements in natural matrix are presented in the frame of EMPIR RPOT1601. Also, some developments are presented in gas chromatography as a result of participating in the EMPIR RPOT1602.
\end{abstract}

\section{Introduction}

At present ever more precise and accurate measurement results support human daily activities and underpin the innovation and economical and social development of each knowledge based economy. In this frame, national measurement standards traceable to the International System of Units (SI) are continuously improved and maintained at National Metrology Institutes (NMIs). Further, the need to demonstrate the equivalence between national measurement standards was required by the global trade and economy as well as the societal challenges. The Recognition Arrangement, CIPM MRA, [1], drawn by the International Committee of Weights and Measures (CIPM) with the authority given it under Article 10 (1921) of the Rules Annexed to the Metre Convention, is the framework through which NMIs demonstrate the international equivalence of their measurement standards and of the calibration and measurement certificates they issue. The CIPM MRA responded to the need for open and comprehensive information on the comparability of the services provided by the NMIs.

\footnotetext{
* Corresponding author: mirella.buzoianu@inm.ro
} 
The signatories of the CIPM MRA recognize the degree of equivalence of the national measurement standards as specified in the Key Comparison Database (KCDB), maintained by the International Bureau of Weights and Measures (BIPM) [2]. Since 1999, when the Recognition Arrangement was signed, the INM, with its responsibility for ensuring the scientific background for the consistency and accuracy of all measurements in Romania, put a lot of effort in developing measurement and calibration capabilities (CMCs), in participating in all field of measurements in relevant comparisons representing the technical basis of the CIPM MRA.

After constant participating in EURAMET comparisons and projects [3], in national research and developing projects and in the European metrology programmes, the outcomes of these efforts became more visible.

Science and research is placed at the core of the development policies of the EU. The societal, technological and economic drivers to modernize the scientific metrology base, and enable it to have a much broader impact, was one of the main reasons for an European Metrology Research Programme (EMRP) that was conceived in 2007. The EMRP has enabled European metrology institutes, industrial organisations and academia to collaborate on joint research projects within specified fields: industry, energy, environment, health, new technologies and SI units. The follow up programme, the European Metrology Programme for Innovation and Research (EMPIR), with an increased focus on innovation, coordinates research projects to address grand challenges, while supporting and developing the SI system of measurement units.

Within this frame the paper presents aspects of the added value brought by the participation of the INM in EMRP/EMPIR. Some outcomes in chemical field as a consequence of participating in several such projects and their impact on the results obtained in different key comparison are presented.

\section{Metrology in chemistry at the INM}

Since 1995 the Metrology in chemistry became a field with very dynamic grow worldwide due to the societal needs for reliable chemical measurements, national legislation and international agreements. Metrological traceability and comparability of the results is required in European cross-border trade, in laboratory medicine, and in transnational implementation of environmental regulations. All European regulations related to the quality of ambient air/working spaces, of drinking water or food safety have been fully implemented in Romania. Most of them include requirements for the accuracy of measurement results, quantification limits or concentration ranges. To meet all these requirements and to achieve the traceability and worldwide comparability of measurement standards represent constant goals for the INM. Present developments in this field of measurements are also related to the need to fulfill certain criteria for the mutual recognition of measurements [1].

Therefore, the INM concentrated on improving a proper and traceable system of national and reference standards in chemical area. The Reference Materials Group organized in the INM is mainly involved in metrology in chemistry related activities. The Group started its activity in 1981 by carrying out calibrations and periodical verifications of analytical spectro(photo)meters (for UV-VIZ mainly) used, by that time, in most diverse industrial and analytical chemistry activities. Later on, as the need for certified reference materials (CRMs) used in connection with other types of spectrometers constant grew, the work of the Group took into consideration the production (in small quantities) and the certification of specific Reference Materials (RMs). Thirty years ago, the Reference Materials Group started its involvement in the certification of some national CRMs (matrix form) and some spectrometric standards, and in different metrological activities related to environment, health and food issues. 
Participation of the Group in national research and development projects ensured developments in technical infrastructure (instruments and operating conditions) able to constant set up new measurement capabilities during the timeframe of 2000-2010.

Using the existing resources and equipment, the Group had also a constant participation, since 2000, in different relevant comparisons and projects, related to matrix materials measurements $[2,3]$ and elemental solutions (EUROMET 763, EURAMET MC1377 and CCQM P46). Different analytical methods were used in these comparisons ranging from UV spectrophotometry, flame (F-AAS) and graphite furnace atomic absorption spectrometry (GFAAS), electrogravimetry and mass spectrometry with inductive coupled plasma (ICP-MS).

However, main developments in metrology in chemistry have been recorded after completing the national research project 3125 entitled 'Researches to establish the best practices to evaluate methodologies highly accurate and sensitive to determine the residues and contaminats', performed during 2007 - 2010. The project was included in the thematic area agriculture, food safety and security having a strong feature of inter and multi-disciplinarity. The research methods taken into consideration were the theory, mathematical model, experiment simulation and evaluation. By means of the activities performed in the project frame two methods, linked to European and international references, were developed - inductively coupled plasma - mass spectrometry and gas-chromatography with mass spectrometer for detection. Using the new GS-MS Clarus 600 and ICP-MS ELAN DRCe II, Perkin Elmer types instruments, methodologies of high accuracy, feasible, sensitive to detect residues of pesticides and contaminants (heavy metals) in food were evaluated, developed and implemented using techniques consistent with the European practice. The project's outcomes ensured the technical conditions to claim at least two CMC, that, later on, were approved and published in BIPM $\mathrm{KCDB}$. Also, conditions were created to develop a program for proficiency testing organized at national level.

In the chemical field, the INM joined several EMRP JRPs in Environment Area (2011) and SI Broader Scope (2012 and 2013). Later on, in 2016 in the frame of the EMPIR, new developments are forseen for production of RMs and for assigning values of mass fraction in different matrices.

\section{European Metrology Programmes support to develop chemical capabilities at the INM}

Metrology research has a public good character and actively supports the policy makers, standardization bodies, industry and academics. To constant align the metrology research with the more demanding, more complex and most urgent societal needs it is necessary to put together a lot of resources (humans, financial, etc.). Often a duplication of research in measurement science was reported. At European level, initiatives were adopted to overcome this situation and to integrate national programmes of the interested participating States.

The EMRP was established in 2009 in partnership by 19 European Member States, Norway, Switzerland and Turkey [4]. Its overall goal was to accelerate innovation and competitiveness, to generate data and knowledge necessary to improve quality of life. By means of European integration, the context of EMRP was to enable Europe to respond to the growing demands for cutting-edge metrology as a tool for innovation, scientific research and support for policy in emerging technological areas in particular [5]. Therefore, the objective of the EMRP was to 'accelerate the development of new measurement capabilities and to significantly improve dissemination and application of knowledge generated throughout the stakeholder community'. The EMRP was the third Article 169 (now Article 185 TFEU) initiative identified in the $7^{\text {th }}$ Framework Programme. During its seven years of life, EMRP supported 119 projects approaching at major European challenges in energy (21 JRPs), environment (19 JRPs), 
industry (30 JRPs), health (24 JRPs), fundamental metrology (24 JRPs related to SI Broader Scope), new technologies (9 JRPs) and open excellence (4 JRPs) [6]

The follow up EMPIR [3] has developed as an integrated part of Horizon 2020, the EU Framework Programme for Research and Innovation being adopted by the Decision 555/2014/EU of the European Parliament and of the Council. The EMPIR aims to reinforce and extend the excellence of the EU's science base and to consolidate the European Research Area in order to make the research and innovation system more competitive on a global scale. Starting 2014, within EMPIR, research projects address grand challenges, while supporting and developing the SI system of measurement units. There is an increased focus within EMPIR on innovation activities to target the needs of industry and accelerate the uptake of research outputs. The EMPIR programme enables European metrology institutes, industrial and medical organisations, and academia to collaborate on a wide variety of joint research projects within specified fields: industry, energy, environment, health, SI Fundamental, Normative, Research Potential, and Support for Networks and Support for Impact projects. The programmes capacity-building projects aim to bridge the gap between EU member states with emerging measurement systems and those with more developed capabilities. Research Potential targeted programme (RPOT) within Capacity Building aim at underpinning the coherent, efficient, sustainable and integrated development of a European metrology capacity landscape. Aspects of participation of the INM in such projects are further presented for environment and food areas.

\section{Development of Calibration and Measurement Capabilities in chemical area}

In accordance with the national needs, firstly, two priority areas have been established for developing calibration and measurement capabilities in the chemical field, i.e elemental calibration solution used in most of the services provided by the INM and measurement of metallic elements in water, as needed to implement and monitor the requirements of the WFD regarding the accepted limits.

Elemental calibration solutions started to be produced at the INM at the beginning of the $90 \mathrm{~s}[7,8]$. Titrimetry was used in the first stage for measuring the mass fraction of the interested elements $(\mathrm{Cu}, \mathrm{Pb}, \mathrm{Zn}, \mathrm{Ca}, \mathrm{Cd}$ etc.) in the calibration solution. This method was also applied in EUROMET 763 project for $\mathrm{Cu}, \mathrm{Pb}, \mathrm{Zn}$ and $\mathrm{Ca}$ [3]. Later on, the F-AAS was applied and reported in several key comparisons. Starting 2010 the ICP-MS is in use. The results reported for $\mathrm{Pb}, \mathrm{Cr}$ and $\mathrm{Co}$ in the key comparison CCQM K87 and for $\mathrm{Al}$ and Mo in EURAMET project MC 1377 were based on ICP mass spectrometry. In 2006 the ISO Guide 34 requirements were implemented in the INM for producing calibration solutions CRMs. By that time, the first CMC on copper calibration solution was approved and published in the BIPM KCDB [2]. It is important to note that present capabilities of the INM to measure the mass fraction of elements in calibration solutions were developed during participation in the EMRP project SIB 09 'Primary standards for challenging elements'. The JRP was carried out during 2012-2015 by 9 partners from eight countries with the coordinator from BAM Germany. The JRP aimed to provide the technical basis to address the lack of primary standards for elemental determination in a sustainable way and within the scope of the worldwide activity of the NMIs. Robust procedures, which encompass the methodology for realizing primary standards fit for most of the challenging elements frequently used in elemental analysis, were developed and applied for five selected elements: $\mathrm{Mg}, \mathrm{Zn}, \mathrm{Mo}, \mathrm{Rh}$ and $\mathrm{Al}$, representatives for a wider group of elements with similar behavior. Within the JRP SIB 09, INRIM, INM, SMU, CENAM and PTB developed different methods to link liquid primary standards to liquid secondary standards with target uncertainties of $U_{\mathrm{rel}}^{r} \leq 0.1 \%$. Within the frame of EURAMET MC1377 comparison [3], organized and performed in 2015 as an activity of the SIB09 Project, these methods were 
validated for elements aluminum and molybdenum. Note that the methods, calibration strategies and approaches developed in this JRP were successfully applied later on in CCQM P149 Zn [9].

Early developments of measurement capabilities of heavy metals in water and their confirmation have based on GF-AAS method, applied during 2007-2008 in the two parts EUROMET 924/EUROMET.QM.S2 project [10]. In the supplementary comparisons SIM QM.S2 and SIM QM.S7 [2] the ICP-MS method was applied using external calibration and standard addition.

During the last five years, INM measurement capabilities expanded to other matrices like soil - confirmed in the CCQM K127, applying both F-AAS and ICP MS, with external bracketing calibration for five analytes (As, $\mathrm{Cd}, \mathrm{Fe}, \mathrm{Pb}$ and $\mathrm{Mn}$ ) [11], powder milk - confirmed in the CCQM K125, applying both F-AAS and ICP MS, with external bracketing calibration for three analytes (Cu, K and I) [12] and human sera-confirmed in the CCQM K139, applying ICP MS with external bracketing calibration and SAD for five analytes $(\mathrm{Cu}, \mathrm{Se}, \mathrm{Cl}, \mathrm{Na}$ and $\mathrm{P})$ [14].

\subsection{Some outcomes of developing copper measurement capabilities in food matrices}

National regulations on food quality added a new priority in developing measurement capabilities with the INM. Based on the experience gained in copper measurements in different matrix, the INM participated in CCQM K125 [12]. The results obtained in this comparison clearly showed the need to further develop and implement the isotope dilution mass spectrometry. This goal is achieved at present in the frame of the EMPIR 16RPT01 ChemMetCap 'Development of scientific and technical capabilities in the field of chemical analysis'. Started at $1^{\text {st }}$ of June 2017, the EMPIR 16RPT01 project is carried out by six partners from France, Romania, Bulgaria, Turkey, Tunisia and Greece, representing NMIs, one DI and one research institute. Coordination of the project is ensured by LNE, France. The ChemMet-Cap project addresses several scientific and technical objectives of interest for the INM such as:

- developing traceable measurement capabilities for the analysis of heavy metals (for concentrations at $\mathrm{ng} / \mathrm{kg}$ and $\mathrm{mg} / \mathrm{kg}$ levels (depending on the matrices) with uncertainties less than $10 \%$ by developing isotope dilution mass spectrometry (ID-ICPMS) methodology as a primary procedure for elemental determination.

- applying the ID-ICPMS methods developed to environmental and food samples to determine the heavy metals content in representative matrices, such as potable and natural waters, sediments, and different types of fish/biota samples.

- validating the developed methods (ID-ICPMS) by participation in suitable international comparisons and hence to underpin the development of appropriate CMCs (Calibration and Measurement Capabilities) for submission to the BIPM Key Comparison Database.

After implementing ICP-MS in 2010, different calibration strategies have been used in order to obtain the lowest possible uncertainty. The first calibration technique applied was the external linear calibration with minimum 5 calibration points and with two points (bracketing calibration) respectively. For metrological applications with the highest requirements for traceability and measurement uncertainty, in the case of trace and ultra-trace element analysis external calibration is challenging due to the inherent problems of preparing standards in such a low concentration range. Often contamination risks, multi-step dilution as well as ad- and desorption effects of lab wares surfaces consistently affect the measurement result. Therefore, only gravimetric procedure is applied. Only glassware cleaned in accordance with a specific implemented procedure are used. However, even if the calibration solutions are careful prepared and the measurement succession is well planned, the instrument drift effects proved to be not negligible when a low uncertainty was needed.

Standard addition method with and without internal standard was applied in the case when the analyte was accompanied by a (complex) sample matrix and the mass fraction to be 
measured was very low (at $\mu \mathrm{g} / \mathrm{kg}$ level) as well as when long-term instrument drifts effects influenced the measurement.

During the EMPIR 16RPT01 ChemMet-Cap project it was developed the direct and reverse isotope dilution. Note that IDMS was recognized the most accurate analytical tool capable of determining the mass fraction of an analyte (element) with lowest associated uncertainty. It provides highest technical quality, it can be completely described and a measurement uncertainty can be derived according to the GUM [13].

In the frame of the project a seabass certified reference material provided by TUBITAK partner was used by the partners to verify and validate the implemented direct ID-ICPMS method for food matrix. Mass fraction of copper, zinc and selenium in the seabass material were measured. For the purpose of this paper only aspects of copper measurement are considered. The measurement procedure applied at INM partner included moisture determination, digestion step of the samples spiked with the isotopes of interest, measurement of isotope ratios, data treatment and measurement uncertainty evaluation and reporting the measurement result. The ERM BB442 Elements in Fish Muscle was subject to the same procedure together with seabass samples. Microwave digestion was applied on amount of samples/ERM BB442 lying in the range of $(0.2 \ldots 0.8) \mathrm{g}$. The moisture of samples was estimated in accordance with the recommendation of TUBITAK and the moisture of the ERM was estimated as indicated in the accompanying documentation. A Copper Isotope standard, Lot \#710941885, produced by VHG-LGC, was used to spike the samples and ERM in the digestion step. The ratios of the isotopes ${ }^{63} \mathrm{Cu}$ and ${ }^{65} \mathrm{Cu}$ were measured with the optimized instrument ELAN DRCe, Perkin Elmer type. Since a preliminary step related to the determination of the isotopic composition on nonspiked samples is included in the measurement procedure, the activity of the INM in the project was completed with additional measurements performed on the same materials (seabass material and ERM BB442) using two-point bracketing calibration and standard addition. This additional activity also intended to compare the performance obtained in previous application of the two calibration methods with the new developed ID-ICPMS. For that purpose, the sample and the ERM were digested without spike using the same digestion program. The mass fraction values of copper in seabass measured using each above mentioned procedure are summarized in Table 1.

Table 1. Mass fraction of copper in seabass

\begin{tabular}{|l|c|c|c|}
\hline & $\begin{array}{l}\text { External } \\
\text { calibration }\end{array}$ & $\begin{array}{l}\text { Standard } \\
\text { addition }\end{array}$ & $\begin{array}{l}\text { ID- } \\
\text { ICPMS }\end{array}$ \\
\hline Certified mass fraction of Cu in seabass, $\mathrm{mg} / \mathrm{kg}$ & \multicolumn{3}{|c|}{$1.20 \pm 0.10$} \\
\hline Mean measured value of mass fraction of $\mathrm{Cu}$ in seabass, $\mathrm{mg} / \mathrm{kg}$ & 1.123 & 1.050 & 1.169 \\
\hline Median value, $\mathrm{mg} / \mathrm{kg}$ & 1.121 & 1.050 & 1.168 \\
\hline Standard deviation of mean, $\mathrm{mg} / \mathrm{kg}$ & 0.010 & 0.132 & 0.009 \\
\hline Number of replicates & 11 & 3 & 7 \\
\hline Expanded measurement uncertainty, $\mathrm{mg} / \mathrm{kg}(k=2)$ & 0.030 & 0.364 & 0.060 \\
\hline
\end{tabular}

Comprehensive evaluation of all sources of uncertainty within the traceability chain was accounted for using basic steps, including a clear definition of the measurand, establishing a model measurement equation, evaluating all sources of uncertainty, generating values of all input quantities and evaluating their standard uncertainties, calculating the output combined standard uncertainty and applying a coverage factor. Accordingly, the measurement equation considered in each case is presented in Table 2. 
Table 2. Measurement equations used in the measurement of mass fraction of copper in seabass

\begin{tabular}{|c|c|c|}
\hline External calibration & Standard addition & ID-ICPMS \\
\hline $\begin{array}{l}\text { where: } \\
-c_{\text {ind }} \text { is the mass fraction } \\
\text { indicated for the digested } \\
\text { sample, in } \mathrm{mg} / \mathrm{kg} \\
\text { - } m_{\text {final dig is the mass of the }} \\
\text { digested solution, g; } \\
\text { - } m_{\text {smp }} \text { is the mass of the } \\
\text { sample taken for digestion, g; } \\
-f_{\text {corr }} \text { moist is the correction } \\
\text { factor for moisture, one; } \\
\text { - } I_{\text {rep }} \text { is an additional } \\
\text { correction factor due to } \\
\text { reproducibility, one. }\end{array}$ & 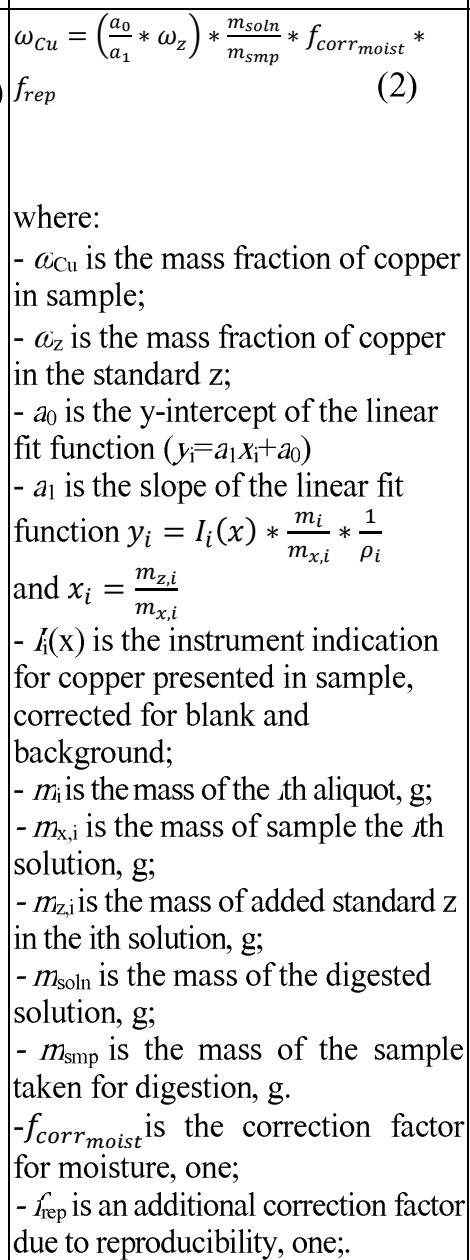 & 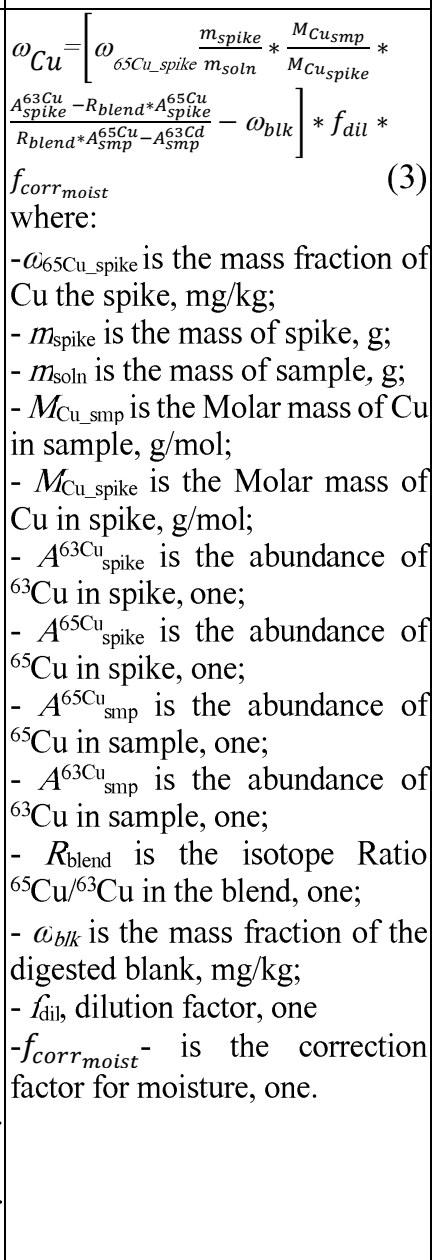 \\
\hline
\end{tabular}

The indicated mass fraction in the case of two points external calibration (bracketing) was calculated based on the instrument indications (i) on sample / standards and the mass fraction (c) of the bracketing standard solutions according to:

$$
c_{\text {ind }}=\frac{\left(I_{s m p}-I_{s t d 1}\right) \cdot\left(c_{s t d 2}-c_{s t d 1}\right)}{\left(I_{s t d 2}-I_{s t d 1}\right)}+c_{s t d 1}
$$

Note that the measurement equation (2) is in accordance with [15] and the equation (3) was developed based on [16]. Starting from these measurement equations, the corresponding measurement budgets are presented in Tables 3 to 5 .

Note that uncertainty due to moisture of the sample was not included in the presented uncertainty budgets, because only measurements on the dried material were performed. 
Table 3. Uncertainty budget in external calibration case

\begin{tabular}{|l|c|c|c|c|}
\hline \multicolumn{1}{|c|}{ Quantity } & Value & $\begin{array}{c}\text { Standard } \\
\text { uncertainty }\end{array}$ & $\begin{array}{c}\text { Probability } \\
\text { distribution }\end{array}$ & $\begin{array}{c}\text { Relative standard } \\
\text { uncertainty }\end{array}$ \\
\hline $\begin{array}{l}\text { mass fraction indicated for the } \\
\text { digested sample, } \boldsymbol{c}_{\text {ind, }} \mu \mathrm{g} / \mathrm{kg}\end{array}$ & 16.105 & 0.154 & normal & 0.00956 \\
\hline $\begin{array}{l}\text { mass of the digested solution, } \\
m_{\text {final_dig, g; }}\end{array}$ & 32.927 & 0.00033 & normal & 0.00001 \\
\hline $\begin{array}{l}\text { mass of the sample taken for } \\
\text { digestion, } m_{\text {smp }}, \mathrm{g} ;\end{array}$ & 0.4771 & 0.00033 & normal & 0.00069 \\
\hline $\begin{array}{l}\text { correction factor for } \\
\text { reproducibility, } \hat{r}_{\text {rep }}\end{array}$ & 1 & 0.00982 & normal & 0.00982 \\
\hline & 1.123 & 0.01542 & & 0.01373 \\
\hline
\end{tabular}

When using the external calibration the measurement uncertainty associated with the indicated concentration and the reproducibility of the measurement method have the largest, almost equal contributions in the combined standard uncertainty.

Table 4. Uncertainty budget in standard addition case

\begin{tabular}{|l|c|c|c|c|}
\hline \multicolumn{1}{|c|}{ Quantity } & Value & $\begin{array}{c}\text { Standard } \\
\text { uncertainty }\end{array}$ & $\begin{array}{c}\text { Probability } \\
\text { distribution }\end{array}$ & $\begin{array}{c}\text { Relative standard } \\
\text { uncertainty }\end{array}$ \\
\hline$a_{0}$ & 57577.19 & & & \\
\hline$a_{1}$ & 7322021 & & & \\
\hline $\begin{array}{l}\text { mass fraction of copper in the } \\
\text { standard } \mathrm{z}, a_{\mathrm{z}}, \mathrm{mg} / \mathrm{kg}\end{array}$ & 1.6388 & 0.02 & normal & 0.01220405 \\
\hline $\begin{array}{l}\text { mass fraction of copper as } \\
\text { indicated, } a_{X S A M}, \mathrm{mg} / \mathrm{kg}\end{array}$ & 15.08782 & 0.0015 & normal & 0.09941794 \\
\hline $\begin{array}{l}\text { mass of the digested solution, } \\
m_{\text {soln }, \mathrm{g}}\end{array}$ & 32.91682 & 0.0002 & normal & 0.00000607 \\
\hline $\begin{array}{l}\text { mass of the sample taken for } \\
\text { digestion, } m_{\text {smp }}, \mathrm{g}\end{array}$ & 0.47707 & 0.00025 & normal & 0.00052403 \\
\hline $\begin{array}{l}\text { correction factor for } \\
\text { reproducibility, } \hat{C}_{\text {rep }}\end{array}$ & 1 & 0.132 & normal & 0.132 \\
\hline$a^{-} \mathrm{X}, \mathrm{mg} / \mathrm{kg}$ & 1.050 & 0.174 & & 0.16570196 \\
\hline
\end{tabular}

When using the standard addition method, the measurement uncertainty associated with the mass fraction indicated on the sample and the reproducibility of the measurement method have the largest contributions in the combined standard uncertainty.

Table 5. Uncertainty budget in ID-ICPMS

\begin{tabular}{|l|c|c|c|c|}
\hline \multicolumn{1}{|c|}{ Quantity } & Value & $\begin{array}{c}\text { Standard } \\
\text { uncertainty }\end{array}$ & $\begin{array}{c}\text { Probability } \\
\text { distribution }\end{array}$ & $\begin{array}{c}\text { Relative } \\
\text { standard } \\
\text { uncertainty }\end{array}$ \\
\hline mass fraction of Cu the spike, $a_{\iota}, \mathrm{mg} / \mathrm{kg}$ & 9.900009 & 0.049550 & normal & 0.0050050 \\
\hline Molar mass of $\mathrm{Cu}$ in sample, $M_{\mathrm{x}}, \mathrm{g} / \mathrm{mol}$ & 63.546 & 0.003 & rectangular & 0.0000472 \\
\hline Molar mass of $\mathrm{Cu}$ in spike, $M_{\mathrm{k}}, \mathrm{g} / \mathrm{mol}$ & 64.985 & 0.003 & rectangular & 0.0000461 \\
\hline mass of sample, $m_{\mathrm{x}}, \mathrm{g}$ & 34.50715 & 0.0002 & normal & 0.0000058 \\
\hline mass of spike, $m_{\mathrm{sp}} \mathrm{g}$ & 0.030997 & 0.0003 & normal & 0.0096785 \\
\hline abundance of ${ }^{65} \mathrm{Cu}$ in sample & 0.69174 & 0.00020 & rectangular & 0.0002891 \\
\hline
\end{tabular}




\begin{tabular}{|l|c|c|c|c|}
\hline abundance of ${ }^{65} \mathrm{Cu}$ in spike & 0.9929 & 0.001 & rectangular & 0.0010071 \\
\hline abundance of ${ }^{63} \mathrm{Cu}$ in spike & 0.0074 & 0.001 & rectangular & 0.1351351 \\
\hline abundance of ${ }^{63} \mathrm{Cu}$ in sample & 0.30826 & 0.00020 & rectangular & 0.0006488 \\
\hline Ratio ${ }^{65} \mathrm{Cu} /{ }^{63} \mathrm{Cu}$ in blend, $R_{\text {blend }}$ & 0.780488 & 0.01155 & normal & 0.0147946 \\
\hline dilution factor, $\digamma_{\text {dil }}$ & 81.54752 & 0.0005 & normal & 0.0000061 \\
\hline mass fraction of the blank, $a_{\text {bll, }} \mathrm{mg} / \mathrm{kg}$ & 0.58144 & 0.0079 & normal & 0.0136038 \\
\hline $\begin{array}{l}\text { mass fraction of } \mathrm{Cu} \text { the sample, } \\
a_{x}, \mathrm{mg} / \mathrm{kg}\end{array}$ & 1.174 & 0.028 & & 0.02433535 \\
\hline
\end{tabular}

The uncertainty associated with the isotopic abundances in natural materials was considered taking into account the IUPAC Technical Report [17]. The uncertainty associated with the isotopic abundances in the spike material was estimated from the available information on similar materials. The measurement uncertainty due to the ratio of isotopes was estimated based on the available information regarding the instrument repeatability and bias. Since the project is in progress a significant decrease in expanded uncertainty is considered.

\subsection{Aspects of developing measurement capabilities for organic analysis}

\subsubsection{Method developed to measure the concentration of PAHs in whole water}

Starting $1^{\text {st }}$ of October 2011, the JRP entitled ENV08 WFD 'Traceable measurements for monitoring critical pollutants under the European Water Framework Directive (WFD2000/60/EC)' was carried out by four NMIs from Germany, France, Romania and Turkey, four DIs from Germany, Slovenia, UK and Finland, the Joint Research Center (IRMM) and one research institute from Germany, integrated as an unfunded JRP-Partner.

In accordance with the requirements of the European WFD (2000/60/EC), also implemented in Romania, the EU Member States have to monitor the ecological status of their surface and coastal waters. In this respect, the project contributed to improve the quality and comparability of such monitoring data and to develop metrology to support research into innovative technologies that mitigate environmental impacts. It directly addressed the need for validated and traceable techniques for measuring concentration of species under regulation and for improving measurement standards for the detection of chemical releases into the environment. Primary reference methods for 3 selected water pollutants (TBTs, PBDE and $\mathrm{PAH}$ ) and concepts for water reference materials were thus developed.

For the INM, the project greatly contributed to develop and implement a reference method for the analysis of polycyclic aromatic hydrocarbons (PAH) in whole water samples at EQS levels. Due to their proven or potential carcinogenic and mutagenic properties PAH are included in Annex X of the WFD as priority hazardous substances. Therefore the aim was to develop a metrologically validated reference procedure for the analysis of PAHs in whole water samples with the limit of quantification (LOQ) of the method smaller than $30 \%$ of the EQS level and the measurement uncertainty less than $50 \%$ at EQS level.

An inventory of European and international standards available at that time showed a lack of applicable method for the eight PAHs of the priority hazardous substances list. Requirements on method sensitivity derived from the proposed EQS for the sums of benzo(b)fluoranthene and benzo(k)fluoranthene $(0.05 \mu \mathrm{g} / \mathrm{L})$ as well as for benzo(g,h,i)perylene and indeno $(1,2,3-$ cd)pyrene $(0.002 \mu \mathrm{g} / \mathrm{L})$, respectively, were lower than the LOQ of the available standards $(0.01$ and $0.005 \mu \mathrm{g} / \mathrm{L}$ ), and hence, difficult to meet. Furthermore, EQS refered to whole water as defined in the WFD to include the dissolved and particulate fraction. Consequently, a method was developed based on EPA Method 610 Polynuclear Aromatic Hydrocabons and on a national procedure applied in some Romanian laboratories specialized in water analysis based on EPA 6440 and EPA 550, respectively. The method covered 11 types of Polynuclear 
Aromatic Hydrocabons in surface waters (rivers, lakes, accumulation lakes), underground waters (drilling) and waste waters (from local sources and general effluents: naphthalene, anthracene, phenanthrene, fluoranthene, benzo(a)anthracene, chrysene, benzo(b)fluoranthene, benzo(k)fluoranthene, benzo(a)pyrene, indeno(123-cd) pyrene, benzo(ghi)perylene.

First challenge was to develop a method capable to extract a low amount of SPM (i.e. up to $500 \mathrm{mg}$ of SPM). For that purpose the liquid-liquid extraction from water sample at a $\mathrm{pH}$ of (6.5 ...7.5) was applied. The ratio between the volume of the water phase and volume of the organic phase (Dichlor-methane) was minimum 20:1. The organic phase extracted, measured in mass and in volume, was concentrated in a Rotavapour, Heidolph type, and the concentrate was measured in mass and transfused in a GC-MS vial. A Clarus 600 GC-MS, PerkinElmer type, was used in measurements. For method validation a TRB- 50 Capillary Column $60 \mathrm{~m} \mathrm{x}$ $0.25 \mathrm{~mm} \times 0.25 \mathrm{um}$ was used. $5 \mu \mathrm{L}$ injection volume and an optimized temperature program were used.

To ensure the comparability of results, the developed method was validated for identification parameters, selectivity, recoveries, limit of detection and limit of quantification, linearity/working range, measurement trueness, measurement precision and measurement uncertainty. The required LOQ of the QA/QC Directive could be achieved for most of the analytes. For indeno(123-c)pyrene and benzo(ghi)perylene the LOQ could be achieved only with a large volume injection in the GC/MS. The method tested met the WFD requirements in term of uncertainty level with $U(k=2)$ less than $50 \%$ at EQS except for benzo(ghi)perylene.

Furthermore, an interlaboratory comparison was organised and performed in the frame of the ENV08 project. The ILC aimed to test the concepts for whole water reference materials developed in the project. Thirteen expert laboratories from eight European countries participated in the ILC together with 11 institutions involved in the ENV08 project. INM participated in the ILC using the developed and validated method with slightly modified instrumental conditions, related to DB-EU PAH ( 60 m length $\times 0.25 \mathrm{~mm}$ ID $\times 0.25 \mu \mathrm{m}$ film) capillary column used and large volume injection $(20 \mu \mathrm{L})$ in a solvent mode. The reported results by the INM are summarized in Table 6 . The results of all participants in the exercise are published in [18].

Table 6. INM reported results on PAH measurements

\begin{tabular}{|c|c|c|c|c|c|c|c|c|c|}
\hline & \multicolumn{5}{|c|}{$\begin{array}{c}\text { Mass fraction, expressed in } \mathrm{ng} / \mathrm{L} \text {, } \\
\text { sample } 1\end{array}$} & \multicolumn{4}{|c|}{$\begin{array}{l}\text { Mass fraction, expressed in } \\
\text { ng/L, sample } 2\end{array}$} \\
\hline & B.1 & B.2 & B.3 & Median & Estim & B.1 & B.2 & Median & Estim \\
\hline Anthracene & 10.3 & 11.7 & 13.7 & $15.1 \pm 6.3$ & 20.6 & 1.3 & 3.8 & $3.3 \pm 1.0$ & 5.7 \\
\hline Fluoranthene & 70.7 & 67.2 & 78.8 & $125 \pm 45$ & 367 & 40.38 & 34.51 & $29.1 \pm 8.4$ & 94.5 \\
\hline Benzo(b)fluoranthene & 63 & 59.9 & 71.9 & $77 \pm 22$ & 120 & 19.3 & 22.4 & $25.7 \pm 4.9$ & 28.7 \\
\hline Benzo(k)fluoranthene & 28 & 27.1 & 32.6 & $47 \pm 20$ & 89 & 8.2 & 9.7 & $10.5 \pm 3.3$ & 13.5 \\
\hline Benzo(a)pyrene & 67.4 & 65.4 & 77.1 & $69 \pm 23$ & 90 & 12 & 15.1 & $12.4 \pm 3.1$ & 14.6 \\
\hline Indeno(1,2,3-cd)pyrene & 58.2 & 55 & 68.2 & $72 \pm 20$ & 101 & 13.9 & 16.2 & $20.6 \pm 4.0$ & 21.6 \\
\hline Benzo(ghi)perylene & 51.5 & 47.4 & 59.7 & $68 \pm 19$ & 118 & 23.1 & 27.6 & $25.6 \pm 3.8$ & 35.6 \\
\hline
\end{tabular}

One may note that due to unexpected analytical problems, naphthalene could not be reported. The results showed an acceptable agreement with the median except for fluorathene in the case of sample 1 . In the sample 2 case, a larger dispersion of the results was noticed for several PAHs. 


\subsubsection{Method developed to measure the mass fraction of ethanol in water samples}

The European status report on road safety of the WHO Regional Office for Europe demands better enforcement of drink-driving legislation in several European countries. The EMPIR 16RPT02 ALCOREF 'Certified forensic alcohol reference materials' project started in 2017 to address this need by building up long term capacities for the production and certification of forensic alcohol reference materials suitable for calibration of evidential breath alcohol analysers as defined by OIML recommendation R 126 [19]. The project is carried out by eight NMIs from Bosnia and Herzegovina, France, Lithuania, Poland, Romania, Serbia, Spain and Turkey, two DIs from Germany and Greece and one university from Poland.

According to the requirements included in the Romanian legislation (Emergency Ordinance $195 / 2002$, updated in 2016), regarding the circulation on public roads, a limit of $0.10 \mathrm{mg} / \mathrm{L}$ ethanol in air breath is accepted. For higher values, but less than $0.40 \mathrm{mg} / \mathrm{L}$ ethanol in air breath, contraventions apply. Driving on public roads with a concentration of ethanol in blood higher than $0.80 \mathrm{mg} / \mathrm{L}$ or with a concentration of ethanol in air breath higher than $0.40 \mathrm{mg} / \mathrm{L}$ is punished by imprisonment. However no measurement uncertainty associated with these values is indicated in the Romanian legislation. In this frame, the activity at the INM concentrated on three mass fraction values of ethanol in water of $0.2500 \mathrm{~g} / \mathrm{L}$ with a target expanded uncertainty $(k=2)$ of $0.0025 \mathrm{~g} / \mathrm{L} ; 1.02920 \mathrm{~g} / \mathrm{L}$ with a target expanded uncertainty $(k=2)$ of $0.0130 \mathrm{~g} / \mathrm{L}$ and $4.0000 \mathrm{~g} / \mathrm{L}$ with a target expanded uncertainty $(k=2)$ of $0.0400 \mathrm{~g} / \mathrm{L}$, respectively.

To meet the overall objective, in the early stages of the project two methods were developed at the INM to measure the mass fraction of ethanol in aqueous solution and to identify and quantify the significant impurities existing in pure ethanol reagent samples. Also, it was implemented the gravimetric procedure to prepare candidate reference materials. After finishing the complete characterization of the materials, i.e. assessment of homogeneity, stability and value assign of property, the reference materials prepared are to be certified. The certified mass fraction value of the reference materials will be based on results obtained from gravimetric preparation and from the analytical results obtained using gas chromatography (GC) with Flame Ionisation Detector (FID).

The method developed to measure the mass fraction of ethanol in aqueous samples is a GCFID one using GC CLARUS 600 Perkin Elmer. The sample, in vapor state, is introduced (automat sampler) in the chromatographic CARBOVAX capillary column 20M having the length of $50 \mathrm{~m}$ and internal diameter of $0.32 \mathrm{~mm}$. The stationary film has a thickness of $0.5 \mu \mathrm{m}$. The temperature program used included the initial temperature of $80{ }^{\circ} \mathrm{C}$ and the final temperature of $180^{\circ} \mathrm{C}$ with a heating rate of $10^{\circ} \mathrm{C} / \mathrm{min} .0 .5 \mu \mathrm{L}$ of sample is injected in Oncolumn mode. The treatment of the acquired data is in accordance with the instrument software and the developed program. Preliminary results obtained at the INM partner in the validation step of the method developed are summarized in Table 7.

In line with developing the GC-FID method to measure the mass fraction of ethanol in aqueous samples, a procedure provided by BAM to prepare the candidate reference materials was implemented at INM. A calibrated mass comparator SARTORIUS AG, ME $614 \mathrm{~S}$ type, was used for ethanol weighting. Also, a calibrated mass comparator SARTORIUS AG, CCE $10 \mathrm{~K} 3$ type was used to weight the needed water.

For the gravimetric procedure it was drafted the uncertainty budget presented in Table 8 , starting from the measurement equation (5).

Table 7. Validated parameters of the GC-FID method developed

\begin{tabular}{|l|l|l|}
\hline Parameter & Target value & Value obtained during validation \\
\hline LOD & $<0.004 \mathrm{~g} / \mathrm{kg}$ & $0.0036 \mathrm{~g} / \mathrm{kg}$ \\
\hline LOQ & $0.02 \mathrm{~g} / \mathrm{kg}$ & $0.012 \mathrm{~g} / \mathrm{kg}$ \\
\hline
\end{tabular}




\begin{tabular}{|c|c|c|}
\hline Repeatability & Less than $0.15 \%$ & $\begin{array}{l}\mathrm{RSD}=0.11 \% \text { at } \omega_{\text {eth }}=0.25 \mathrm{~g} / \mathrm{kg} \\
\mathrm{RSD}=0.07 \% \text { at } \omega_{\text {eth }}=1.0641 \mathrm{~g} / \mathrm{kg} \\
\mathrm{RSD}=0.08 \% \text { at } \omega_{\text {eth }}=4.0 \mathrm{~g} / \mathrm{kg}\end{array}$ \\
\hline Trueness & $0.3 \%$ for $\omega_{\text {eth }} \geq 1 \mathrm{~g} / \mathrm{kg}$ & $\begin{array}{l}1.11 \% \text { at } a_{\text {eth }}=0.25 \mathrm{~g} / \mathrm{kg} \\
0.17 \% \text { at } a_{\text {eth }}=1.0641 \mathrm{~g} / \mathrm{kg} \\
0.21 \% \text { at } a_{\text {eth }}=4.0 \mathrm{~g} / \mathrm{kg}\end{array}$ \\
\hline $\begin{array}{l}\text { Measurement } \\
\text { uncertainty }\end{array}$ & $\begin{array}{l}L=2.20 \% \text { at } \omega_{\mathrm{eth}}=0.25 \mathrm{~g} / \mathrm{kg} \\
L=0.56 \% \text { at } \omega_{\mathrm{eth}}=1.0641 \mathrm{~g} / \mathrm{kg} \\
L=0.56 \% \text { at } \omega_{\mathrm{eth}}=4.0 \mathrm{~g} / \mathrm{kg}\end{array}$ & $\begin{array}{l}L=2.58 \% \text { at } \omega_{\mathrm{eth}}=0.25 \mathrm{~g} / \mathrm{kg} \\
L=0.38 \% \text { at } \omega_{\mathrm{eth}}=1.0641 \mathrm{~g} / \mathrm{kg} \\
L=0.45 \% \text { at } \omega_{\mathrm{eth}}=4.0 \mathrm{~g} / \mathrm{kg}\end{array}$ \\
\hline Linearity & $\begin{array}{l}\mathrm{R}^{2}>0.995 \\
\text { relative residual standard } \\
\text { deviation } \mathrm{S}_{\mathrm{rr}}<0.02\end{array}$ & $\begin{array}{l}\mathrm{R}^{2}=0.9965 / \mathrm{S}_{\mathrm{rr}}=0.0012 \text { at } \omega_{\mathrm{eth}}=0.25 \mathrm{~g} / \mathrm{kg} \\
\mathrm{R}^{2}=0.9994 / \mathrm{S}_{\mathrm{rr}}=0.0010 \text { at } \omega_{\mathrm{eth}}=1.0641 \mathrm{~g} / \mathrm{kg} \\
\mathrm{R}^{2}=0.9998 / \mathrm{S}_{\mathrm{rr}}=0.0004 \text { at } \omega_{\mathrm{eth}}=4.0 \mathrm{~g} / \mathrm{kg}\end{array}$ \\
\hline
\end{tabular}

(5)

$$
\omega_{\text {sol }}=\frac{m_{e} * P^{*} f_{\text {evap }}}{m_{\text {sol }}}
$$

where: $a_{\text {sol }}$ is the mass fraction of ethanol in the final solution, in $\mathrm{g} / \mathrm{kg}$;

$m_{e}$ is the mass of ethanol (with buoyancy correction), in g;

$P$ is the purity of ethanol, one;

$f_{\text {evap }}$ is the correction factor for the evaporation, one;

$m_{s o}$ is the mass of solution (with buoyancy correction), in kg.

Table 8. Uncertainty budget for the gravimetric procedure applied to prepare the candidate reference materials of ethanol in water

\begin{tabular}{|l|l|l|l|}
\hline Quantity & Value & $\begin{array}{l}\text { Standard } \\
\text { uncertainty }\end{array}$ & $\begin{array}{l}\text { Relative } \\
\text { standard } \\
\text { uncertainty }\end{array}$ \\
\hline mass of ethanol, $m_{\text {Etha }}, \mathrm{g}$ & 5.00000 & 0.00033 & 0.000066 \\
\hline mass of water, $m_{\text {water }} \mathrm{g}$ & 5005.0000 & 0.0000121 & $2.417 .10^{-9}$ \\
\hline Purity of ethanol reagent, $P$ & 0.99944 & 0.00006 & 0.000006 \\
\hline correction factor for the evaporation, $C_{\text {evap }}$ & 1 & 0.000006 & 0.000006 \\
\hline correction factor due to method reproducibility, i $_{\text {iepeat }}$ & 1 & 0.0032 & 0.00332 \\
\hline mass fraction of ethanol in final solution, $\boldsymbol{C}_{\text {ett }}, \mathrm{g} / \mathrm{kg}$ & 1.0289 & 0.003294 & 0.003201249 \\
\hline
\end{tabular}

The correction factor due to the evaporation was put into evidence by performing two independent series (2 different operators and 2 different balances) of ongoing mass measurements on an open vial. The pooled standard deviation of the two independent measurement series was considered. The mass fraction of the ethanol reagent used in the gravimetric procedure was estimated based on the water content measured using coulometric Karl Fisher (cKF) method and mass fraction of the major organic impurity identified in the reagent (n-propanol). Note that the cKF method was developed and used in EMRP JRP SIB064 for solid samples. Reproducibility of the gravimetric procedure showed the greatest contribution to the standard combined uncertainty.

A homogeneity studies was performed on the prepared batches. Stability study started last November and is still in progress. Two interlaboratory comparisons are envisaged in the next stages of the project to test the materials and capabilities developed so far. 


\section{Conclusions}

The paper presented selected outcomes of the participation of the INM in several EMRP/EMPIR projects. The added value of the research activities performed in national and European metrology related projects is reflected in developing and implementing new measurement methods (GC-MS and IDICP-MS) of organic and inorganic species consistent with the European and international practice. The reported results clearly showed an improvement in the existing capabilities during last decade. Participating in such research projects allowed INM to also demonstrate its capabilities in relevant comparisons organized and performed either during or after the European projects ended.

\section{References}

1. Mutual recognition of national measurement standards and of calibration and measurement certificates issued by national metrology institutes (1999), https://www.bipm.org/utils/ en/pdf/CIPM-MRA-2003.pdf

2. www.bipm.kcdb.org

3. www.euramet.org

4. Decision No 912/2009/EC of the European Parliament and of the Council on the participation by the Community in a European metrology research and development programme undertaken by several Member States, OJ L 257 (2009)

5. European Metrology Research Programme, Outline 2008, Edition November 2008

6. www.emrp.org

7. M. Buzoianu, Fresenius J.Anal.Chem., 370:151-155 (2001)

8. M. Buzoianu, Fresenius J.Anal.Chem., 370:170-177 (2001)

9. J.Vogel et.al., Metrologia 55, 211-221 (2018)

10. Final Report EUROMET.QM.-S2 'Determination of $\mathrm{Hg}, \mathrm{Cd}, \mathrm{Pb}$ and $\mathrm{Ni}$ in pure and natural water at concentration levels required by the European Water Framework Directive, (2009), https:/www.bipm.org/utils/common/pdf/final_reports/QM/S2/EUROMET.QM-S2.pdf

11. M. Rocio Arvizu Torres, et.aı., Metrologia 54, Tech. Suppl., 08010 (2017)

12. J. Merrick, et.al., Metrologia 54, Tech. Suppl., 08013 (2017)

13. JCGM 100:2008 Evaluation of measurement data - Guide to the expression of uncertainty in measuremeni, https:/www.bipm.org/utils/common/documents/jcgm/JCGM 1002008 E.pdf

14. R. Shin et.a., Metrologia 55, Tech. Suppl., 08006 (2018)

15. A.L. Hauswaldt, O. Rienitz, R.Jahrling, N.Fischer, D.Schiel, G.Labarraque, B.Magnusson, Accred.Qual.Assur, 17:129-138 (2012)

16. R.L. Watters Jr, K.R. Eberhardt, E.S Beary, J.D.Fasset, Metrologia, 34:87-96 (1997)

17. J.Meija et.aı. Pure Appl.Chem. 88(3): 293-306 (2016)

18. J.Richter, et.a., Accreditation and Quality Assurance, Volume 21, Issue 2, pp 121-129 (2016)

19. OIML R126 'Evidential breath analyzers', edition 2012 